\title{
Calcium-based mixed oxide catalysts for methanolysis of Jatropha curcas oil to biodiesel
}

\begin{abstract}
Calcium-based mixed oxides catalysts $(\mathrm{CaMgO}$ and $\mathrm{CaZnO})$ have been investigated for the transesterification of Jatropha curcas oil (JCO) with methanol, in order to evaluate their potential as heterogeneous catalysts for biodiesel production. Both $\mathrm{CaMgO}$ and $\mathrm{CaZnO}$ catalysts were prepared by coprecipitation method of the corresponding mixed metal nitrate solution in the presence of a soluble carbonate salt at $\sim \mathrm{pH} 8 \mathrm{i} 9$. The catalysts were characterized by X-ray diffraction (XRD), temperature programmed desorption of $\mathrm{CO} 2$ (CO2-TPD), scanning electron microscopy (SEM) and N2 adsorption (BET). The conversion of JCO by $\mathrm{CaMgO}$ and $\mathrm{CaZnO}$ were studied and compared with calcium oxide $(\mathrm{CaO})$, magnesium oxide $(\mathrm{MgO})$ and zinc oxide $(\mathrm{ZnO})$ catalysts. Both $\mathrm{CaMgO}$ and $\mathrm{CaZnO}$ catalysts showed high activity as $\mathrm{CaO}$ and were easily separated from the product. $\mathrm{CaMgO}$ was found more active than $\mathrm{CaZnO}$ in the transesterification of JCO with methanol. Under the suitable transesterification conditions at $338 \mathrm{~K}$ (catalyst amount $=4 \mathrm{wt} . \%$, methanol/oil molar ratio $=$ 15 , reaction time $=6 \mathrm{~h}$ ), the JCO conversion of more than $80 \%$ can be achieved over $\mathrm{CaMgO}$ and $\mathrm{CaZnO}$ catalysts. Even though $\mathrm{CaO}$ gave the highest activity, the conversion of JCO decreased significantly after reused for forth run whereas the conversion was only slightly lowered for $\mathrm{CaMgO}$ and $\mathrm{CaZnO}$ after sixth run.
\end{abstract}

Keyword: Biodiesel; Transesterification; Jatropha curcas oil; Heterogeneous catalysts; Calcium-based mixed oxide 